\title{
Os efeitos do crack na gestação e nos bebês nascidos de mães usuárias: Uma revisão bibliográfica ${ }^{1}$
}

\author{
Paola de Oliveira Camargo ${ }^{a}$, Maria de Fátima Duarte Martin ${ }^{b}$ \\ aPrograma de Pós-graduação em Enfermagem, Universidade Federal de Pelotas - UFPel, Pelotas, RS, Brasil

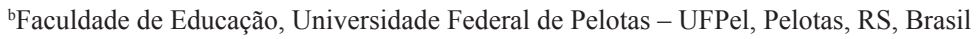

\begin{abstract}
Resumo: Considerando o significativo aumento no consumo de crack na população brasileira, estudos referentes a essa temática aparecem timidamente a partir da primeira década do século XXI. A mídia se encarrega de abordar o tema através do seu alto poder de penetração na sociedade, com discurso preconceituoso, de exclusão. Por essa razão estudos realizados por profissionais e pesquisadores são necessários. Quando se fala dos efeitos do crack em crianças, estudos ficam ainda mais escassos. Para este artigo, buscou-se a partir de uma revisão bibliográfica conhecer o que está sendo estudado sobre os possíveis efeitos do uso de crack na gestação. Utilizou-se como fonte o Banco de Teses e Dissertações da Capes, os bancos de dados Medline, Lilacs, e sites de órgãos públicos ligados à saúde, com os descritores "cocaína-crack", "feto", "recém-nascido", "gravidez". A busca ocorreu em 2012/2013 e foram incluídas as publicações de 2000 a 2013, escritas em português, espanhol e inglês. A amostra foi constituída de 3 teses, 7 dissertações e 28 artigos, escolhidos após leituras de resumo e posterior leitura na íntegra. Observou-se que há avanço no interesse pela temática, embora ainda haja lacunas em relação ao tema oriundas da área da antropologia, sociologia e psicologia, prevalecendo os estudos de ordem biológica. Constatou-se que podem ocorrer alguns danos devido à exposição pré-natal de crack em crianças filhas de mães usuárias, mas os efeitos em longo prazo ainda não podem ser comprovados, visto que os fatores externos ao uso da droga também podem estar diretamente relacionados a essas consequências.
\end{abstract}

Palavras-chave: Cocaína Crack, Feto, Recém-nascido, Gravidez.

\section{The effects of crack in pregnancy and babies of addicted mothers: A literature review}

\begin{abstract}
Considering the significant increase in crack use in the Brazilian population, studies on this subject have appeared timidly as of the first decade of this century. The media is responsible for addressing the issue through its high penetration in society with a limited speech, that of exclusion. For this reason, studies by experts and researchers are needed. When speaking of the effects of crack in children, studies are even scarcer. The purpose of this article was to carry out a literature review to know what is being studied about the possible effects of crack use during pregnancy. To this end, a search was conducted at the following database: CAPES - Theses and Dissertations, MEDLINE, LILACS, and sites of public agencies related to health, using the descriptors "crack cocaine", "fetus", "newborn", and "pregnancy". The search occurred in 2012/2013 and publications from 2000 to 2013, written in Portuguese, Spanish and English were included. The sample consisted of three theses, seven dissertations, and 28 articles, chosen after reading the summary and further reading in full. It was possible to observe that there has been advancement in the interest for the area, although there are still gaps in relation to the issue arising in the field of anthropology, sociology and psychology, with prevalence of biological studies. We found that some damage may occur due to prenatal exposure to crack in children of addicted mothers, but the long-term effects cannot yet be proven, since factors external to drug use can also be directly related to these consequences.
\end{abstract}

Keywords: Crack Cocaine, Fetus, Newborn, Pregnancy.

Autor para correspondência: Paola de Oliveira Camargo, Universidade Federal de Pelotas, Campus Porto, Rua Gomes Carneiro, 01, Porto, CEP 96010-610, Pelotas, RS, Brasil, e-mail: paolacamargo01 @ hotmail.com

Recebido em 28/8/2013; Revisão em 18/2/2014; Aceito em 4/5/2014. 
As drogas, mesmo o crack, são produtos químicos sem alma: não falam, não pensam e não simbolizam. Isso é coisa de humanos. Drogas, isso não me interessa. Meu interesse é pelos humanos e suas vicissitudes. (Antonio Nery Filho, 2010).

\section{Introdução}

\subsection{Falando sobre o crack}

"O crack é uma substância psicoativa euforizante (estimulante), preparada à base da mistura da pasta de cocaína com bicarbonato de sódio" (UNIDADE..., 2011, p. 9), que pode ser obtida de duas maneiras, através do pó ou da pasta base, ambos derivados da cocaína. Após alguns tratamentos químicos, o resultado é uma pedra, de cor branca ou amarelada, dependendo dos ingredientes utilizados e sua proporção. Essa pedra possui, então, os mesmos princípios ativos da cocaína, porém com efeitos diferentes devido a sua forma e composição, que por ser volátil, ou seja, por poder ser fumada, atinge o sistema nervoso central em segundos, sendo absorvida mais rapidamente pelas vias pulmonares, se tornando uma droga tão potente (DOMANICO, 2006).

Por ser eficientemente absorvido e pelos efeitos gerados serem táo mais intensos se comparados à cocaína em pó, causa também uma dependência mais rápida, levando o indivíduo a querer utilizar novamente em poucos minutos, o que explica a famosa "fissura". Sendo esse um dos primeiros efeitos, juntamente com a euforia, sensaçáo de poder e autoconfiança, momentos de prazer e excitação, falta de apetite, reduçáo do frio e do sono, motivo pelo qual muitos moradores de rua utilizam a substância, como forma de amenizar e saciar suas necessidades básicas (NAPPO et al., 2004).

Após as sensaçôes de bem-estar, surgem os efeitos negativos da droga, associados aos da fissura e da necessidade de consumir mais e mais a substância. Alguns dos efeitos causados pelo uso do crack são: dilatação das pupilas, hipertensão, convulsões, sudorese, tremores intensos, taquicardia e até mesmo o coma pode ocorrer durante os momentos de uso. Observam-se também a falta de cuidados de higiene e mudança nos hábitos alimentares. Alguns casos mais graves podem levar até mesmo à morte, devido à diminuição da atividade dos centros cerebrais, responsáveis pelo controle da respiração (CARLINI et al., 2001).

\subsection{Chegada do crack no Brasil}

O crack, derivado da cocaína, começou a ser comercializado no Brasil em uma época na qual os insumos químicos utilizados para a confecçáo da cocaína, como o éter e a acetona, começaram a ficar indisponíveis no mercado devido ao alto controle governamental sobre a comercialização dessas substâncias. A partir desse evento, traficantes iniciaram a produção de uma droga menos pura, mais barata e, portanto, facilmente mais vendável. Essa droga ficou conhecida como crack, devido ao barulho que faz ao ser fumado (DOMANICO, 2006).

O crack aparece no Brasil a partir dos anos 1990 e daquele período até hoje foi tratado pela mídia como uma epidemia. Ao tratar o tema dessa forma, transforma-o em uma problemática que estigmatiza aqueles que a usam, tornando-os temidos pelos demais. A mídia associa o crack à violência e ao tráfico, provocando preconceito contra os usuários, que passam a ser uma ameaça para a sociedade. Pela complexidade da temática, para Outeiral (2003), médico psiquiatra, o problema transcende os âmbitos familiares e requer um movimento da sociedade como um todo, em seus vários aspectos, tais como os que envolvem a ética e a política.

Sobre a chegada do crack, tanto no Brasil, como no restante do mundo, há poucas informaçôes científicas. A maioria das informaçôes encontradas é derivada da imprensa leiga ou de órgáos policiais, ambos geralmente trazendo informaçóes distorcidas da realidade. O que sabemos é que o crack vem ganhando espaço nas ruas de nosso país, principalmente reforçado pela repressáo policial, pelo ambiente de exclusão e pelo fanatismo da mídia brasileira (DIMENSTEIN, 1999).

\subsection{Políticas públicas: Pequenos passos}

Se pensarmos em políticas sociais e econômicas, ambas estão em constante transformação, assim como o perfil dos usuários de crack. Uma pesquisa quantitativa, realizada em território nacional pelo grupo de pesquisadores Francisco Inácio Bastos e Neilane Bertoni, da Fundação Oswaldo Cruz (Fiocruz) em parceria com a Secretaria Nacional de Políticas sobre Drogas (Senad), entre os anos de 2011 e 2013 e divulgadas no dia 19 de setembro de 2013, mostra resultados diferentes do que muitas vezes a mídia divulga. Das 26 capitais brasileiras, incluindo o Distrito Federal, nove regióes e municípios de médio e pequeno porte, tiveram como resultado estimado 
que existam aproximadamente 370 mil usuários de crack. Sendo que nessas mesmas cidades, o cálculo para usuários de drogas ilícitas equivale a um milhão de pessoas, ou seja, o número de consumidores de crack corresponde a $35 \%$ das pessoas que fazem uso de drogas ilícitas no país (FIOCRUZa, 2013).

Em relação a questôes de gêneros, a pesquisa demonstra que as mulheres fazem um uso mais intenso da droga do que comparado aos homens. Apesar da média de seis anos para as mulheres e sete para os homens, quando se pensa no consumo diário as mulheres consomem 21 pedras e os homens cerca de 13. Essas mulheres muitas vezes reportam já ter sofrido violência sexual ao menos uma vez na vida, um quadro chocante que nos mostra o quanto dentro dessa população de usuários de drogas, que são excluídos, essas mulheres são mais excluídas ainda, mais vulneráveis e necessitadas de atenção (FIOCRUZb, 2013).

Uma pesquisa como essa, realizada a partir de uma metodologia inédita no Brasil, foi a única até o momento capaz de estimar de forma mais precisa essa populaçấo de difícil acesso. Principalmente por nos mostrar dados importantíssimos acerca dessa população, demonstrando estimativas referentes ao fato de que cerca de $10 \%$ das mulheres entrevistadas relataram estar grávidas e mais da metade das usuárias já havia engravidado ao menos uma vez depois que iniciou o uso de drogas.

Ainda faltam políticas públicas que acessem diretamente esses usuários, embora pequenos passos venham sendo dados, através de grandes investimentos do governo federal para a prevenção, e o combate a essa droga, como, por exemplo, o Programa de Reduçáo de Danos, oferecido pelo Ministério da Saúde, o qual trata-se de um conjunto de políticas e práticas cujo objetivo é reduzir os danos associados ao uso de drogas psicoativas em pessoas que não podem ou não querem parar de usar drogas. Por definição, redução de danos foca na prevenção aos danos já instaurados, foca em pessoas que seguem usando drogas. O programa complementa outras medidas que visam diminuir o consumo de álcool, crack e outras drogas, como um todo (BRASIL, 2013).

As pesquisas e os estudos sobre o tema drogas, e principalmente o uso de crack, aos poucos vão aparecendo na literatura. Até pouco tempo a mídia era quem abordava o tema, na maioria das vezes através de campanhas preconceituosas, de cunho sensacionalista, que estigmatizaram a imagem dos usuários, associando-os à violência e à marginalidade, jogando a população contra esse grupo de pessoas.

\section{$1.4 O$ crack na gestação}

Os efeitos do uso do crack pela gestante sobre o feto e o recém-nascido, foco dessa revisão, constituem um importante tópico de saúde pública, devido à incidência alta e cada vez maior dessa droga no mundo e aos possíveis efeitos no bebê, quando a mãe usa a droga durante a gestação. Para preencher as lacunas existentes quanto aos resultados de estudos e pela complexidade do tema, procurou-se conhecer, a partir do que está referenciado na literatura, quais seriam as possíveis consequências geradas pelo uso do crack na gestaçáo e até que ponto elas podem ser transmitidas ao feto em desenvolvimento.

O maior problema para que se possam avaliar os efeitos diretos das drogas sobre o feto é a grande variedade de fatores de risco, como sociodemográficos, psicossociais, comportamentais e biológicos que se relacionam diretamente com as drogas e as consequências na gravidez. A pobreza, a falta de cuidado pré-natal, as doenças sexualmente transmissíveis e a desnutrição são sérios problemas sociais e que podem contribuir para que o número de mulheres usuárias de drogas cresça e consequentemente o número de crianças que podem vir a nascer nesta situaçấo também (BRASIL, 2012b, p. 233-234).

Estudos que tratam sobre o consumo de drogas entre as mulheres, em especial entre as mulheres gestantes, são extremamente raros e pontuais, o que nos mostra uma urgência em estudos científicos que busquem maior aprofundamento no assunto, para que esse tema tão importante náo continue passando despercebido por nós profissionais ou tenha visibilidade apenas através da mídia, que leva informações muitas vezes inadequadas à população, só aumentando a exclusão e o afastamento dessas mulheres e em geral de todos os usuários de drogas da sociedade.

Como hombres de ciência, hemos dedicado años al estúdio de lós efectos de las drogas em el cérebro y el comportamiento [...] Pero, sorprendentemente, es poca la información que le ha llegado efectivamente a la opinión pública. Estamos convencidos de que las actuales campañas de información sobre lós efectos del alcohol y otras drogas son inadecuadas y están mal dirigidas (KUHN; SWARTZWELDER; WILSON, 2011, p. 13-14). 


\section{Materiais e métodos}

Trata-se de uma pesquisa bibliográfica, que sintetiza estudos realizados sobre um tema específico, bem como identifica e problematiza os resultados. Inicialmente realizou-se uma pesquisa nas bases de dados eletrônicos: Medical Literature and Retrieval System on Line (Medline), Literatura LatinoAmericana e do Caribe em Ciências da Saúde (Lilacs) e portal Scientific Eletronic Library, assim como buscas nos bancos de teses e dissertações da Coordenação de Aperfeiçoamento de Pessoal de Nível Superior (Capes). Os descritores que orientaram a busca foram: cocaína crack, recém-nascido, feto e gravidez.

A realizaçáo da coleta ocorreu durante o ano de 2012, vindo a ser revisada no ano de 2013. Inicialmente foram lidos todos os títulos encontrados que tivessem relação com os descritores escolhidos. A partir de então, alguns artigos já foram sendo excluídos, por não se tratarem do objeto da pesquisa. Após foram lidos todos os resumos restantes, acontecendo a exclusão de mais alguns artigos, por não se tratarem efetivamente do uso de crack durante a gestação e os efeitos nos bebês nascidos nessas situaçôes. Esses passos foram respeitados tanto nas buscas de artigos como na procura de teses e dissertaçôes; após seleção por resumos, todos os trabalhos restantes foram lidos na íntegra, chegando ao número final de sete dissertaçôes, três teses e 28 artigos que respondiam à questão orientadora deste artigo. Outras leituras, tais como livros, entrevistas na internet, sites do governo e revistas não indexadas, subsidiaram a pesquisa.

Os artigos escolhidos foram publicados entre os anos de 2000 e 2013. Devido ao fato de o assunto ser pouco estudado e os trabalhos serem escassos, se o tempo de publicação fosse diminuído muitos trabalhos seriam perdidos.

Encontrou-se um grande número de publicações quando usado separado o descritor cocaína crack, mas esse mesmo número decresce bastante quando acrescentado aos outros descritores, que têm uma relação mais profunda com o conteúdo do trabalho. Com relação ao número de publicações, a área da saúde aparece em primeiro lugar, seguida pelas áreas da sociologia e antropologia.

\section{Resultados e discussão}

Foi encontrado um total de 49 artigos pertinentes à temática. Após avaliação criteriosa do conteúdo e sua relaçáo com o tema em estudo, foram excluídos 21 artigos, por não responderam à questão de investigação do trabalho. Logo a amostra foi constituída por 28 artigos que tratavam diretamente sobre o tema e podem ser encontrados durante a leitura deste trabalho. Todas as teses e dissertaçóes encontradas durante a revisão bibliográfica fazem parte do trabalho aqui apresentado.

Ao analisarem-se os resultados, observou-se que a maioria das publicaçóes apontava que os efeitos do uso de crack durante a gestação estavam associados na maioria das vezes às causas biológicas em detrimento aos efeitos relacionados com problemas sociais. Esse fato pode ser em razão da maioria dos estudos serem oriundos da área médica.

Segundo a médica psiquiátrica e seus colaboradores, Marques et al. (2012), estudos qualitativos com usuários de crack só começaram a ser publicados no Brasil no início da década de 1990, e estudos de acompanhamentos de dependentes, apenas a partir da segunda metade dos anos 2000. Em relação aos estudos que tratam sobre o consumo de drogas entre as mulheres, esses são ainda mais escassos e corroboram com a necessidade de mais estudos sobre o tema.

Em um estudo realizado com mulheres, para as pesquisadoras Rotta e Cunha (2000), a exposição pré-natal a drogas pode potencialmente levar o recém-nascido a apresentar sintomas relacionados a intoxicação ou abstinência. Para as autoras, o que foi constatado até agora é que a ação da droga pode ser forte, e, dependendo da quantidade ingerida, também pode causar alteraçôes na capacidade de contração do útero, ocorrendo em alguns casos deslocamento prematuro da placenta, sangramentos anormais e até mesmo o aborto espontâneo, sendo assim as consequências do uso de drogas durante a gestação são multifatoriais. Os efeitos do crack no bebê podem ser observados das mais diversas formas, dependendo desde a quantidade ingerida pela máe até o uso concomitante de outras drogas ou até mesmo o fato de ter sido realizado ou não o pré-natal durante a gravidez.

Outro estudo realizado pela médica neonatologista Gabrielle Cunha, da Universidade Federal do Rio Grande do Sul (UFGRS), a qual vem desde 1994 estudando o uso de drogas durante a gravidez, constata que os bebês expostos ao crack durante o período fetal náo nascem necessariamente dependentes da droga. E para a pesquisadora, até o momento não há nenhuma comprovação científica de que estes desenvolvam abstinência na ausência da substância (CUNHA, 2000).

Quando a pessoa que usa drogas é uma mulher há uma maior desaprovação social, o que contribui 
para que elas façam uso de drogas às escondidas e aumente assim a vulnerabilidade a diversos riscos e danos à saúde (OLIVEIRA; PAIVA, 2007).

Segundo Wright e Walker (2007), mulheres grávidas e usuárias de drogas muitas vezes podem encontrar barreiras quando procuram algum tipo de acesso à saúde e, sentindo que os cuidados básicos ao qual têm direito não lhe são acessíveis, acabam por procurar ajuda tardiamente ou apenas quando já estáo em trabalho de parto, momento em que a maioria nega o uso de drogas, por medo da rejeição ou até mesmo da perda do filho.

O tratamento pré-natal de acordo aos estudos aqui citados pode ser um fator de proteçấo. A grande maioria das gestantes dependentes químicas não faz nenhum tipo de acompanhamento pré-natal e nem procura orientaçôes médicas durante a gravidez, pois sua rotina se faz nas ruas, com o uso de drogas. Elas costumam chegar à maternidade apenas na hora do parto e isso acaba dificultando ainda mais a identificação delas e do número de crianças nascidas nessa situação.

A infrequente procura por ajuda e o baixo acesso aos serviços da rede de saúde por parte da população usuária de álcool e outras drogas em situação de rua, em especial as crianças, adolescentes e jovens, e ainda o predomínio de ofertas de cuidado baseadas na abstinência como objetivo exclusivo e de abordagens terapêuticas desenvolvidas quase exclusivamente no interior de instituiçôes de saúde, têm excluído grande parte dos usuários das açóes de assistência e prevenção (BRASIL, 2010b, p. 4).

O Ministério da Saúde tem buscado intervir nas causas e efeitos do consumo de drogas, em conjunto com outras políticas sociais, como, por exemplo, a implementação dos Consultórios na Rua.

O Consultório na Rua tem como princípios norteadores o respeito às diferenças, a promoção de direitos humanos e da inclusão social, o enfrentamento do estigma, as açôes de redução de danos e a intersetorialidade" (BRASIL, 2010a, p. 5).

Ações desse tipo tornam mais fáceis e acessíveis para as gestantes usuárias de crack a realização do pré-natal no próprio local em que fazem o uso da droga, sem que tenham que enfrentar a dificuldade de atendimento na procura de hospitais, por estarem sujas, sob o efeito da droga ou simplesmente pela exclusão que sofrem de toda a sociedade, um dos principais motivos pelo qual, muitas vezes, não procuram atendimento e ajuda.

\subsection{Mitos e verdades}

Sobre os efeitos do crack nos bebês filhos de mães usuárias, os estudos ainda são poucos e de certa forma contraditórios. Não há uma verdade uniforme. Para Rotta e Cunha (2000, p. 184): "Caracteristicamente esses bebês são pouco responsivos, facilmente irritáveis e difíceis de interagir". As mesmas autoras abordam em seus estudos sobre os altos níveis de ansiedade, depressão e de estresse relatados pelas mães, além da dificuldade das crianças em se manterem concentradas e cooperarem em atividades, assim como atitudes mais desordenadas, diminuindo a capacidade de simbolizar e de criar, havendo menos representaçóes.

White e Lambe (2003), estudiosos do Departamento de Anestesia do Hospital St. Thomas, em Londres, no Reino Unido, relatam que drogas como a cocaína podem suprimir o apetite e dessa forma os usuários acabam por comprar mais drogas no lugar de alimentos e como consequência desta alimentação não nutritiva há também o risco de agravamento de outras patologias associadas com a substância ingerida. Dessa forma, os filhos nascidos de máes usuárias podem nascer com baixo peso, desnutridos e estarem expostos a riscos de adoecimento. Essa desnutrição pode estar diretamente ligada aos efeitos citados acima.

Lindow (2004) sugere que o uso da cocaína está frequentemente relacionado com o descolamento prematuro da placenta, assim como com partos prematuros, ruptura uterina, disritmias cardíacas, isquemia cerebral, infarto e morte. Esses efeitos, como já citado anteriormente, dependem de vários fatores, como a dose ingerida, o tempo de consumo, a idade gestacional e, principalmente, o consumo de outras substâncias, juntamente com o crack, que pode agravar mais ainda esses efeitos.

Novamente citando White e Lambe (2003), em seus estudos acerca dos efeitos do crack no feto, relatam possível teratogenicidade humana, inclusive anomalias, microcefalia, defeitos no tubo neural, retardo do crescimento e até mesmo efeitos em longo prazo se mostram aparentes.

Lindow (2004) cita problemas como dificuldade de sucção, de alimentação, irritabilidade, hipertonia, bocejos e espirros como sintomas de abstinência experimentados pelos recém-nascidos, ao contraposto de Simpson e McNulty (2008) que já afirmam que não existem evidências confiáveis de que realmente há essa crise de abstinência e que possa causar algum tipo de dano permanente.

Segundo os estudos da médica neonatologista Hallam Hurt, que desde 1989 vem trabalhando com esse tema, especialmente com o uso da cocaína 
e seus efeitos, tendo os resultados de seus estudos apresentados no Children's Hospital of Filadélfia, onde atua. Hurt et al. (2009) constata que os efeitos da droga não são tão graves se comparados à pobreza, que pode prejudicar muito mais o desenvolvimento infantil do que o consumo de alguma substância por parte da mãe na gestação, ou seja, o ambiente familiar, as condições sociais, o acesso a um bom pré-natal são fundamentais para que a criança possa se desenvolver. O real problema é a pobreza e a falta de acesso a um bom pré-natal, medicamentos e alimentação, e não apenas o uso da cocaína.

Andrade e Santiago (2008) trazem em seus estudos o alastramento do crack em outras classes sociais. Embora ainda seja extremamente forte a associação dessa substância à pobreza e à violência, seu consumo vem crescendo também entre as outras classes sociais. Se pensarmos no acesso a um bom pré-natal, um bom atendimento de saúde e uma boa alimentação, as classes menos favorecidas acabam sendo prejudicadas e isto pode estar relacionado a problemas futuros no desenvolvimento, reforçando os estudos de Hurt (2009).

Um dos grupos de referência em estudos do crack na gestação e no bebê é o da professora americana Emmalee S. Bandstra, professora de pediatria, obstetrícia e ginecologia da Universidade de Miami. A pesquisadora realizou um estudo no final dos anos 90, para o qual foram recrutados 476 recém-nascidos (nenhum prematuro) com o objetivo de realizar um amplo estudo sobre os efeitos da exposiçâo à cocaína e ao crack durante a gestação. Metade das mães usava drogas de forma frequente e a outra metade não usava. $\mathrm{O}$ estudo, ainda em andamento, deu origem a vários artigos científicos e jogou para o campo da discussão as verdades e mitos sobre os efeitos do crack nos bebês. $\mathrm{O}$ estudo também avaliou as funçôes intelectuais e a capacidade de aprendizagem das crianças filhas de usuários quando ingressaram na escola (aproximadamente sete anos de idade). O estudo demonstrou que o risco de apresentar dificuldades de aprendizagem foi três vezes mais elevado no grupo de crianças que teve contato com a droga (GUINSBURG, 2013).

Sobre esses efeitos, alguns estudos também afirmam que algumas alteraçóes no sistema nervoso central da criança ainda podem se manifestar durante o período escolar, sendo as mais comuns os déficit de atenção e as dificuldades de aprendizagem. Porém essas hipóteses não foram comprovadas e os fatores que envolvem as dificuldades escolares são complexos e não podem ser reduzidos apenas à área médica.
A medida que lós primeros grupos de ninõs expuestos a la cocaína han ido llegando a la escuela, lós investigadores há encontrado incidências más altas de problemas de aprendizaje y síndrome de déficit de atención com hiperatividad, como es el caso de niños nacidos de madres fumadoras durante el embarazo (KUHN; SWARTZWELDER; WILSON, 2011, p. 167).

Para Marques et al. (2012, p. 15),

[...] a síndrome da abstinência da cocaína neonatal é caracterizada pela presença de irritabilidade, hipertonicidade, tremores, alteraçóes do humor e impossibilidade de consolo.

Outros autores também corroboram com Marques et al. (2011) quanto aos efeitos nos bebês nascidos de mulheres que fizeram uso de alguma substância na gestação, relatando consequências devido ao uso do álcool e da cocaína:

Pero si lós bebês llegan al final del embarazo, las consecuencias para muchos de ellos pueden no ser tan drásticas. Em cuanto a defectos de nacimiento, se registran pequenos incrementos, pero este no es el mayor problema para lós bebes como lo es para aquellos que estàn expuestos a altos niveles de alcohol durante el embarazo. Muchos bebês expuestos a la cocaína son muy irritables y demasiado sensible e cualquier tipo de estimulación sensorial al nacer (KUHN; SWARTZWELDER; WILSON, 2011, p. 166-167).

Shenna Prentice (2010) traz informaçóes sobre outro aspecto importante quando envolve exposição pré-natal ao crack e recém-nascidos, sugerindo que a amamentação deve ser incentivada, pois os benefícios para o bebê superam qualquer risco e o prolongado contato físico entre a mãe e seu filho leva ao ganho de benefícios significativos de saúde e de crescimento infantil, caso o bebê tenha nascido prematuro, assim como aumenta também o afeto materno, diminuindo possíveis comportamentos agressivos da mãe.

O Ministério da Saúde, em publicação das Diretrizes Gerais Médicas para Assistência Integral ao Crack, do ano de 2012, aconselha e apoia as mães que amamentam a não usarem nenhum tipo de droga. Para o Ministério da Saúde o conselho dado às mães com transtornos por uso de drogas é que devem amamentar seus filhos pelo menos durante os seis primeiros meses, a menos que haja 
recomendação de um especialista para não que não haja a amamentação (BRASIL, 2012a).

A partir do que foi apresentado até agora se pode pensar o quanto este tema é complexo e contraditório, pois especialistas, médicos e o próprio Ministério da Saúde encontram divergências ao lidar com o tema. Ainda há controvérsias quando o tema é o uso de drogas e a gestação. Vale lembrar, porém, que o número de estudos para que possamos afirmar o real impacto do uso do crack no desenvolvimento infantil ainda é pequeno e novas pesquisas se fazem necessárias.

Aproximando-se dos dias de hoje, para Marques et al. (2012), a relação entre a exposiçáo ao crack durante a gestação e a presença de prejuízos no desenvolvimento neuropsicomotor é inconsistente e controversa.

Alguns fenômenos relacionados com o uso de cocaína durante a gestação, tais como os efeitos da substância no desenvolvimento gestacional, tanto na mãe (placenta, infecçóes etc.) como no feto, assim como a presença da síndrome de abstinência logo após o nascimento, têm chamado a atençáo dos pesquisadores e profissionais da saúde (MARQUES et al., 2012, p. 14).

\section{Conclusões finais}

A partir dos resultados deste estudo, é possível concluir que os achados vão ao encontro das consideraçôes de Glauser e Queen (2007). Para esses autores, a real extensão dos danos que o uso do crack pode causar na gravidez é até hoje desconhecida, precisando mais estudos nessa área. Para Prentice (2010), os efeitos em longo prazo do uso de drogas na gravidez são ainda mais difíceis de serem detectados, devido aos raros estudos longitudinais sobre o assunto. Outro fator que dificulta a avaliação dos efeitos do crack na gestação e nos bebês nascidos de mães usuárias é o uso concomitante de outras drogas, assim como as impurezas encontradas nas drogas de rua, que vêm decrescendo a "qualidade" devido ao interesse financeiro dos traficantes.

Segundo Cruz (2012, p. 49), “[...] tendo em vista a dimensão do problema da droga no país, é inconcebível a falta de produção científica em relação ao tema”. No Brasil, para a autora, existem poucos estudos científicos sobre as consequências do crack no desenvolvimento fetal, bem como no desenvolvimento da criança.

Para Prentice (2010), fazem-se necessários mais estudos longitudinais e pesquisas que abordem o tema fora do ponto de vista da polícia e da mídia, pois os estudos existentes são poucos e não têm acompanhado o número de usuários, que está crescendo demasiadamente.

Constatou-se a necessidade de mais comprometimento dos órgãos governamentais responsáveis com as políticas públicas em atenção, prevenção e cuidado da saúde. Campanhas e açóes preventivas são importantes, assim como programas de apoio ao usuário, sem visar apenas tirá-los da visibilidade e sim levar à recuperação e ao acompanhamento do dependente e apoio a sua família dentro de uma política de cuidado e atenção.

O tema crack merece, assim como os seus usuários, uma atenção multidisciplinar. Diálogos entre os profissionais das diversas áreas são importantes para dar visibilidade ao tema. E precisam-se desses profissionais, de debates com a sociedade e de consultas aos usuários para que haja embasamento teórico suficiente para saber lidar com o assunto sem preconceito.

O uso de drogas na população geral permanece um sério problema a ser solucionado e que deve envolver equipes multidisciplinares em sua abordagem. Especificamente em relação ao uso de drogas na gravidez, um maior número de trabalhos deve ser desenvolvido na tentativa de se estabelecer a melhor estratégia de abordagem para esse segmento específico da população (YAMAGUCHI et al., 2008, p. 5).

Para finalizar, embora o tema não se esgote aqui, pretende-se com este artigo trazer para os leitores alguns dados sobre o que está publicado atualmente sobre a temática, e chamar atenção para a necessidade de ampliar os debates sobre o uso do crack numa perspectiva coletiva, na qual participem das discussóes as diversas áreas do conhecimento. Os estudos aqui abordados apontam para a necessidade de mais projetos voltados para a saúde da população e de cuidado aos usuários de drogas, incluindo cuidados materno-infantis, forma de internação, atendimento às famílias, programas de lazer para os jovens, entre outras formas de cuidado na tentativa de erradicar o uso do crack nas geraçóes futuras.

Para Cunha (2000), apesar de os efeitos do crack não serem sempre catastróficos, eles existem e são graves. Portanto, não podemos negar a gravidade do tema e a necessidade de ser abordado e discutido sem preconceito, sem medo, sem violência, sem repressão, e sim como um problema de saúde pública com sérias consequências negativas para toda a sociedade. 


\section{Referências}

ANDRADE, T. M.; SANTIAGO, L. A farmacologia social do crack: o uso do "pitilho" (cigarro de crack e maconha) entre jovens moradores de distritos pobres da cidade de Salvador - Bahia - Brasil. Bahia: ARD-FC; Universidade Federal da Bahia, 2008. Disponível em: <http://www. slideshare.net/flaviocampos/artigo-sobre-crack-rd>. Acesso em: 22 ago. 2013.

BRASIL. Ministério da Saúde. Consultório de rua do SUS. Brasília, 2010a. Disponível em: <http://portal.saude.gov. br/portal/arquivos/pdf/consult_rua17_1_11.pdf> Acesso em: 14 jan. 2013.

BRASIL. Ministério da Saúde. Departamento de Açôes Programáticas Estratégicas. Coordenação Nacional de Saúde Mental, Álcool e outras Drogas. Consultórios de Rua do SUS. Brasília, 2010b. 48 p. Disponível em: <http://www.defensoria.sp.gov.br/dpesp/Repositorio/31/ Documentos/consultorio_rua_SUS.pdf> Acesso em: 25 ago. 2012.

BRASIL. Portal Brasil. Crack, é possivel vencer. Brasília, 2012a. Disponível em: <http://www2.brasil.gov.br/ crackepossivelvencer/efeitos-e-consequencias/gestantee-bebe> Acesso em: 2 fev. 2013.

BRASIL. Ministério da Saúde. Secretaria de Atenção à Saúde. Departamento de Ações Programáticas Estratégicas. Gestação de alto risco: manual técnico. 5. ed. Brasília, 2012b.

BRASIL. Ministério da Justiça. Secretaria Nacional da Política sobre Drogas. Prevenção do uso de drogas: capacitação para conselheiros e lideranças comunitárias. 5. ed. Brasília, 2013.

CARLINI, E. A. et al. Drogas psicotrópicas: o que são e como agem. Revista IMESC, São Paulo, n. 3, p. 9-35, 2001.

CRUZ, V. D. Vivencias de mulheres de consomem crack em Pelotas-RS. 2012. 112 f. Dissertação (Mestrado em Ciências)-Universidade Federal de Pelotas, Pelotas, 2012.

CUNHA, G. B. Epidemiologia da exposiçāo pré-natal à cocaina em uma amostra de recém-nascidos do HCPA. 2000. 128 f. Dissertação (Mestrado)-Universidade Federal do Rio Grande do Sul, Porto Alegre, 2000.

DIMENSTEIN, G. Repressáo amplia limites da cracolândia. Folha de São Paulo, São Paulo, v. 11, p. 3-8, 1999.

DOMANICO, A. Craqueiros e cracados: bem vindo ao mundo dos nóias! Estudo para a implementação de estratégias de redução de danos para usuários de crack nos cinco projetos-piloto do Brasil. 2006. 220 f. Tese (Doutorado em Ciências Sociais)-Universidade Federal da Bahia, Salvador, 2006. PMid:16955285.

FUNDAÇÃO OSWALDO CRUZ - FIOCRUZ. Estimativa do número de usuários de crack elou similares nas Capitais do País. Rio de Janeiro, 2013a. Disponível em: <http://portal. mj.gov.br/services/DocumentManagement/FileDownload. EZTSvc.asp? DocumentID $=\{9 \mathrm{~B} 17 \mathrm{D} 77 \mathrm{~F}-\mathrm{C} 442-4 \mathrm{~B} 2 \mathrm{~B}-$ $8705-117920$ F30 C6F $\} \&$ ServiceInstUID $=\{74624 \mathrm{DEB}-$
0C14-4B3A-B8F3-CD26DEF53FC1\}>. Acesso em: 12 fev. 2014.

FUNDAÇÃO OSWALDO CRUZ - FIOCRUZ. Perfil dos usuários de crack elou similares no Brasil. Rio de Janeiro, 2013b. Disponível em: <http://portal.mj.gov. $\mathrm{br} /$ services/DocumentManagement/FileDownload. EZTSvc. asp? DocumentID $=\{0 F C D C 036-D 0 A F-$ 4EDB-B2D5-140DF943F56C $\} \&$ ServiceInstUID $=\{74$ 624DEB-0C14-4B3A-B8F3-CD26DEF53FC1\}>. Acesso em: 12 fev. 2014

GLAUSER, J.; QUEEN, J. R. An overview of non-cardiac cocaine toxicity. The Journal of Emergency Medicine, Philadelphia, v. 32, n. 2, p. 181-186, 2007. PMid:17307630. http://dx.doi.org/10.1016/j.jemermed.2006.05.044

GUINSBURG, R. Reanimação neonatal em sala de parto. Sociedade Brasileira de Pediatria, 2013. (Documento Científico do Programa de Reanimação Neonatal). Disponível em: <http://www.sbp.com.br/pdfs/ PRN-SBP-Reanima\%C3\%A7\%C3\%A3oNeonatalF inal-2011-25mar11.pdf >. Acesso em: 10 maio 2013.

HURT, H. et al. Children with and without gestational cocaine exposure: a neurocognitive systems analysis. Neurotoxicology and Teratology, New York, v. 31, n. 6, p. 334-41, 2009. PMid:19686843 PMCid:PMC2765041. http://dx.doi.org/10.1016/j.ntt.2009.08.002

KUHN, C.; SWARTZWELDER, S.; WILSON, W. Colocados: tudo lo que hay que saber sobre las drogas más concumidas, desde el alcohol hasta el éxtasis. 1. ed. Buenos Aires: Debate, 2011.

LINDOW, S. W. Obstetric implications of cocaine use in pregnancy: a literature review. European Journal of Obstetrics, Gynecology and Reproductive Biology, Amsterdam, v. 112, n. 1, p. 2-8, 2004. http://dx.doi. org/10.1016/j.ejogrb.2003.08.005

MARQUES, A. C. P. R. et al. Abuso e dependência: crack. Revista da Associação Médica Brasileira, São Paulo, v. 58, n. 2, p. 141-153, 2012. http://dx.doi.org/10.1590/ S0104-42302012000200008

NAPPO, A. S. et al. Comportamento de risco de mulheres usuárias de crack em relação às DSTIAIDS. São Paulo: CEBRID, 2004.

NERY FILHO, A. O crack é feito com a raspa do chifre do diabo. In: ______. Conversando com Antonio Nery Fillho: Drogas: isso lhe interessa? Maio 2010. Disponível em: $<$ http://conversandocomnery.wordpress.com/2010/05/>. Acesso em: 30 jun. 2013.

OLIVEIRA, J. F.; PAIVA, M. S. Vulnerabilidade de mulheres usuárias de drogas ao HIV/AIDS em uma perspectiva de gênero. Escola Anna Nery Revista de Enfermagem, Rio de Janeiro, v. 11, n. 4, p. 625-631, 2007. OUTEIRAL, J. Adolescer: estudos revisados sobre a adolescência. 2. ed. Rio de Janeiro: Revinter, 2003.

PRENTICE, S. Substance misuse in pregnancy. Obstetrics, Gynaecology and Reproductive Medicine, Kidlington, v. 20, n. 9, p. 278-283, 2010. 
ROTTA, N. T.; CUNHA, G. B. Exposição pré-natal à cocaína: revisão dos efeitos neurocomportamentais. Jornal de Pediatria, Rio de Janeiro, v. 76, n. 3, p. 179-184, 2000.

SIMPSON, M.; MCNULTY, J. Different needs: women's drug use and treatment in the UK. The International Journal on Drug Policy, Liverpool, v. 19, n. 2, p. 169-175, 2008. PMid:18155515. http://dx.doi. org/10.1016/j.drugpo.2007.11.021

UNIDADE DE PESQUISAS EM ÁLCOOL E DROGAS - UNIAD. Cartilha sobre o crack. Brasília: CNJ, 2011. Disponível em: <http://www.uniad.org.br/ desenvolvimento/images/stories/arquivos/cartilhacrack. PDF>. Acesso em: 20 ago. 2012.
WHITE, S. M.; LAMBE, C. J. T. The pathophysiology of cocaine abuse. Journal of Clinical Forensic Medicine, Edinburgh, v. 10, n. 1, p. 27-39, 2003. http://dx.doi. org/10.1016/S1353-1131(03)00003-8

WRIGHT, A.; WALKER, J. Management of women who use drugs during pregnancy. Seminars in Fetal \& Neonatal Medicine, Amsterdam, v. 12, n. 2, p. 114-118, 2007. PMid:17336173. http://dx.doi.org/10.1016/j. siny.2007.01.001

YAMAGUCHI, E. T. et al. Drogas de abuso e gravidez. Revista de Psiquiatria Clínica, Sáo Paulo, v. 35, p. 44-47, 2008. Suplemento 1.

\section{Contribuição das Autoras}

Paola de Oliveira Camargo: Responsável pela elaboração da pesquisa e autora do texto. Maria de Fátima Duarte Martins: Orientadora da pesquisa e co-autora do texto.

\section{Notas}

${ }^{1}$ Pesquisa bibliográfica realizada para concluir o curso de Especialização em Educação Infantil na Universidade Federal de Pelotas, RS, e que está sendo desenvolvida no Mestrado em Enfermagem da mesma instituição. O texto já foi apresentado em congressos e outros eventos. 